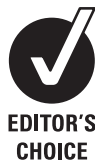

CHOICE

\title{
Television food advertising directed towards Bulgarian children
}

\author{
S V Galcheva, ${ }^{1}$ V M lotova, ${ }^{1}$ V K Stratev ${ }^{2}$
}

${ }^{1}$ Department of Paediatrics and Medical Genetics, Varna

University Hospital "St. Marina", Varna, Bulgaria; ${ }^{2}$ Department of Internal Diseases, Varna Military Hospital, Varna, Bulgaria

Correspondence to:

Dr Sonya Vasileva Galcheva,

Department of Paediatrics and

Medical Genetics, Varna

University Hospital "St. Marina",

1. Hristo Smirnenski str, Varna

9010, Bulgaria:

sonya_galcheva@mail.bg

Accepted 1 April 2008

Published Online First 2 May 2008

\section{ABSTRACT}

Background: Childhood obesity is a serious health problem worldwide with a prevalence rising to epidemic proportions. Television viewing is suspected as an important contributor and along with food advertisements significantly influence children's unhealthy dietary habits, purchase requests and adiposity.

Objectives: To examine the exposure of Bulgarian children to television food advertising and to make a content analysis of the food/beverage advertisements during children's television programmes.

Design: $41.5 \mathrm{~h}$ of children's television programming on three national networks, were videotaped. All recorded food advertisements were evaluated to identify the marketing strategies used for the stimulation of children's purchase requests.

Results: Food/beverage advertisements accounted for 124 (33.4\%) of all commercials, with $96.8 \%$ being for unhealthy foods. $57 \%$ of them were aimed specifically at children as the most advertised products were salty/ sweetened snacks and cereals, sweets, soft drinks/ carbohydrate juices and salty foods, with no fruit or vegetable commercials. Food advertisements used more themes of adventure, animation, music and gifts to attract children's attention, and gave information based on the product's taste, physical qualities, novelty, presence of premiums/prizes. Of all food/beverage advertisements, $27.4 \%$ contained health-related information about the products; three-quarters of the advertisements were shot with young normal-weight actors with a good/healthy appearance.

Conclusion: Almost all recorded food advertisements do not support the Bulgarian dietary recommendations for healthy and balanced eating. More activities to reduce the unhealthy food promotion to children are mandatory as restrictions by type of advertised food, target group or limits on the advertisements' account and times shown, as well as parental/self-regulation.

Childhood obesity is a serious health problem worldwide with a prevalence lately rising to epidemic proportions. It tends to track into adulthood-that is, obese children are likely to remain obese adults, with an increased risk of morbidity, mortality and healthcare costs. ${ }^{1}$

Childhood obesity in Bulgaria is increasing as in the rest of the developed countries, although the rise is at a lower rate. ${ }^{2}$ Investigating potential contributors to this trend is an important step in designing prevention policies. Among those, television (TV) viewing is suspected as a major contributor, playing an important role in children's everyday life, even in those younger than 2 years of age. ${ }^{4}$

Although the issue of how food advertising is connected to the epidemic of childhood obesity, is an

\section{What is already known on this topic}

- Television watching and exposure to food advertising is only one amidst a variety of environmental, social and personal factors of impact on the development of poor eating habits and overweight and obesity in children.

- Food marketing to children is dominated by "unhealthy" foods and beverages using sophisticated marketing strategies to promote products to children.

- Regulatory approaches exist in the majority of the developed countries to restrict advertising during children's viewing hours.

\section{What this study adds}

- Despite the increasing rate of childhood obesity in Bulgaria and the existing dietary recommendations for healthy and balanced eating, children are exposed to numerous food advertisements high in fats, sugar and/or salt with no fruit/vegetable commercials during children's TV programmes.

- There is an alarming need for specific regulations for TV food advertising directed to children in Bulgaria.

ongoing controversial debate, there is evidence that TV watching and food advertisements (ads) significantly influence a variety of children's behavioural practices such as unhealthy dietary habits, ${ }^{5-7}$ purchase requests for high-calorie low-nutrient products $^{89}$ and adiposity. ${ }^{10-12}$ Previous studies have found that the most advertised products are fast foods, soft drinks, sweets and other rich-in-calories foods of poor nutritional value..$^{14}{ }^{14}$ Since children are vulnerable to the food messages portrayed through a TV ad, misconceptions about the health benefits of the advertised foods may develop, their increased consumption may follow ${ }^{15}$ and fruit and vegetable consumption may be reduced. ${ }^{16}$

The aim of the current study is to examine the exposure of Bulgarian children to TV food advertising and to make a content analysis of the TV food/ beverage ads during children's TV programmes.

\section{METHODS}

\section{Design}

The study was conducted between 17 February and 2 March 2007, with no public and school 
holidays or other special events during the data collection. A total of $41.5 \mathrm{~h}$ of all children's TV programmes, aired between 06:00 and 18:30 on three national TV stations - one public (Canal 1) and two private (NTV, BTV) - were videotaped and analysed on two weekdays and both weekend days for each network. All ads aired during the recorded period were included in the analysis.

In order to identify the marketing strategies used for the stimulation of food purchases, we evaluated 19 signs: the day of recording; the presenting TV station; the viewing hours early morning (06:00-09:30), late morning/lunch time (09:30-13:00), afternoon (14:30-18:30); children's programme type (animation, show, TV game, children's serial/movie); the commercial's length; its format (animated, non-animated or mixed); the type of the advertised product (non-food, healthy or unhealthy food/beverage); the type of promoted foods/beverages; the way of stimulation of the brand purchase (direct or indirect messages); information provided for the product, including verbal or visual information related to physical and mental health; marketing methods and associations used to appeal, persuade and stimulate the purchase request; direction to the child/adult/general audience; human characters participating in the ads (age, sex, weight/body size, shown eating or not), etc.

\section{Statistical analysis}

All data were analysed with the SPSS 15.0 statistical package, applying one-way analysis of variance (ANOVA), correlation and multiple-logistic regression analysis. We used a $p$ value of less than 0.05 to determine statistical significance.

\section{RESULTS}

The $41.5 \mathrm{~h}$ of recorded and analysed children's programmes included a total of 371 commercials ( 8.9 ads per hour), mostly aired on the two private TV stations (98\%) vs $2 \%$ on the public TV network. A total of 2 h 52 minutes (6.9\%) of the videotaped programmes were devoted to commercials. Food and beverage ads accounted for 124 (33.4\%) of all ads broadcasted during the study period, with $96.8 \%$ being for unhealthy foods. The majority of the latter were for high-calorie sugar- (62\%), fat$(61 \%)$ and salt- $(22 \%)$ containing foods. Therefore the children were exposed to 2.99 food ads per hour, lasting an average of $23.6(\mathrm{SD}=7.3$ ) seconds. About $57 \%$ of all food ads were aimed entirely at the child audience (presence of child/adolescent actor, verbal appeals to children), 16\% were directed to the adult audience and around $27 \%$ to the general audience (in the absence of the above-mentioned clues).

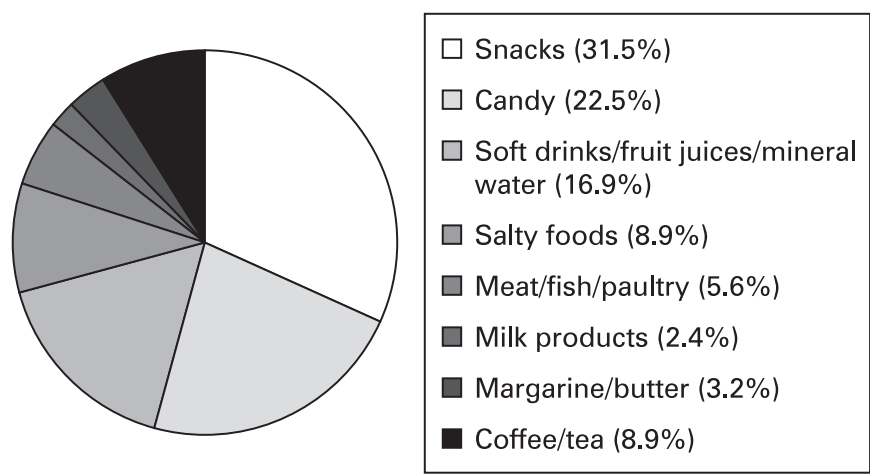

Figure 1 Relative share of the advertised foods/beverages on Bulgarian television stations.
The advertised food and beverage products, their distribution in eight food categories and the frequency of advertising are presented in fig 1 . The most frequently advertised products were salty/sweetened snacks and cereals, sweets, soft drinks/ carbohydrate juices and foods high in salt. There were no fruit or vegetable commercials.

The ads for chocolates and carbohydrate juices had the longest mean length (28.8 and 28.1 seconds), and the shortest were the ads for margarine (13.7 seconds). Most frequently animated were the ads for snacks (77\%), carbohydrate juices $(43 \%)$ and chocolates (41\%). No animation techniques were used in the ads for dairy products.

We investigated if there were any differences in the advertised food groups according to the weekdays and programmes (tables 1 and 2, respectively). A significant association was found between the advertised food and the day of advertising $(p<0.001)$. More than half of the recorded food/beverage ads $(55 \%)$ were broadcasted during the weekend days $(p<0.001)$. There was a significant difference in the advertised food groups recorded during different children's programmes $(p<0.001)$, as the ads for sweets were aired mainly during children's movies, soft drinks' ads during animation and the snacks' ads during animation or children's shows for music/sports/pets. The regression analysis confirmed a significant dependence between the type of the advertised food and the day $(r=-0.41)$, TV station $(r=-0.02)$, programme $(r=0.35)$ and air time $(r=0.36)(p<0.001)$.

The advertised food category correlated significantly with the programmes' air time $(r=0.36, p<0.001)$. In the early morning when $46 \%$ of all food ads were broadcasted, those for snacks $(82 \%)$ and soft drinks (57\%) prevailed. Around lunch time (34\% of food ads) and in the afternoon, meat, dairy and salty products commercials prevailed.

The main product information provided to children was based on the food's taste (68.5\%), physical qualities (48\%), novelty $(29 \%)$, composition and content $(25 \%)$, presence of premiums and prizes - cards, stickers and electronic games (24\%). Information about the product's price was significantly more rare (3.2\%). The most common and popular appeals/ associations were with lovely/magnificent taste (76\%), smile/ fun/happiness (50\%), singing and dancing (32\%), celebrities/ stars $(24 \%)$, love emotions (19\%), pleasure while consuming the food $(12 \%)$ and adventure/action/sport (11\%).

Of all 124 food/beverage ads, $27.4 \%$ contained direct or indirect health-related "favourable" information about the products, such as an increased fibre content, addition of vitamins and minerals (vitamin C, calcium, magnesium), lowcalorie content, low or no fat, sugar and/or salt content, provision with natural essential nutrients, or gave just a simple message as "good or wholesome food product".

Table 1 Distribution of food advertisements according to the day of broadcasting

\begin{tabular}{lcl}
\hline Advertised food products & Weekday $(\mathbf{n})(\%)$ & Weekend day $(\mathbf{n})(\%)$ \\
\hline Snacks $(\mathrm{n}=39)$ & $7(18)$ & $32(82)$ \\
Candy $(\mathrm{n}=28)$ & $16(57)$ & $12(43)$ \\
Soft/sweetened drinks/mineral water & $7(33)$ & $14(67)$ \\
$(\mathrm{n}=21)$ & & \\
Salty foods $(\mathrm{n}=11)$ & $7(64)$ & $4(36)$ \\
Meat/fish/poultry $(\mathrm{n}=7)$ & $4(57)$ & $3(43)$ \\
Milk products $(\mathrm{n}=3)$ & $1(33)$ & $2(67)$ \\
Margarine/butter $(\mathrm{n}=4)$ & $2(50)$ & $2(50)$ \\
Coffee $(\mathrm{n}=11)$ & $11(100)$ & $0(0)$ \\
Fruit/vegetables $(\mathrm{n}=0)$ & $0(0)$ & $0(0)$
\end{tabular}


Table 2 Distribution of food advertisements according to the programme type

\begin{tabular}{lllll}
\hline Advertised food products & $\begin{array}{l}\text { Animation } \\
(\mathbf{n})(\%)\end{array}$ & $\begin{array}{l}\text { Children's show } \\
(\mathbf{3 0 \%})^{*}(\mathbf{n})(\%)\end{array}$ & $\begin{array}{l}\text { Children's movie/ } \\
\text { serial }(\mathbf{4 8 \%})^{*} \\
(\mathbf{n})(\%)\end{array}$ & $\begin{array}{l}\text { TV game (11\%)* } \\
(\mathbf{n})(\%)\end{array}$ \\
\hline Snacks $(\mathrm{n}=39)$ & $17(43.6)$ & $20(51.3)$ & $1(2.6)$ & $1(2.6)$ \\
Candy $(\mathrm{n}=28)$ & $1(4)$ & $6(21)$ & $17(61)$ & $4(14)$ \\
Soft/sweetened drinks $(\mathrm{n}=21)$ & $8(38)$ & $4(19)$ & $7(33)$ & $2(10)$ \\
Salty foods $(\mathrm{n}=11)$ & $0(0)$ & $4(36.4)$ & $5(45.4)$ & $2(18.2)$ \\
Meat/fish/poultry $(\mathrm{n}=7)$ & $0(0)$ & $4(57)$ & $3(43)$ & $0(0)$ \\
Milk products $(\mathrm{n}=3)$ & $1(33.3)$ & $1(33.3)$ & $1(33.3)$ & $0(0)$ \\
Margarine/butter $(\mathrm{n}=4)$ & $0(0)$ & $4(100)$ & $0(0)$ & $0(0)$ \\
Coffee $(\mathrm{n}=11)$ & $0(0)$ & $0(0)$ & $8(73)$ & $3(27)$ \\
Fruit/vegetables $(\mathrm{n}=0)$ & $0(0)$ & $0(0)$ & $0(0)$ & $0(0)$ \\
\hline
\end{tabular}

*Relative share of a certain type of shows of all recorded time is shown as percentages in brackets.

In $77 \%$ of the food/beverage ads, a young actor (child/ adolescent), was shot, with a normal weight and good/healthy appearance. Male characters, participating in the one-gender ads, slightly outnumbered females (17\% and $15 \%$, respectively). The character was shown consuming the advertised food/ beverage in $85 \%$ of all the commercials, and in $100 \%$ of those for snacks and sweets.

The indirect stimulation of purchase requests prevailed and there was a significant correlation between the food type and the way of stimulation $(\mathrm{r}=0.2, \mathrm{p}<0.05)$. The most frequent marketing methods, used to attract the children's attention, to stimulate and persuade the brand requests, are presented in fig 2.

\section{DISCUSSION}

The vast majority of research work shows that television viewing and exposure to food advertising is one amidst a variety of environmental, social and personal factors of impact on the development of poor eating habits and overweight/obesity in children. $^{3} 510131517$

Children are targeted aggressively by food advertisers and marketers, and exposed to a growing amount of advertising during TV programmes, aiming to influence their brand preference and choices, food purchases and intake. ${ }^{514} 15$ 18-26 In 1996 an international comparative survey of children's TV advertising showed that the exposure varied between 10 and 12 ads per hour in Australia, the USA and the UK, 2 times less in France, Germany and Denmark and 2-3 ads per hour in Austria and Belgium. ${ }^{27}$ The least amount of food advertising was found in Sweden with almost no food commercials ( $<1 \mathrm{ad} /$ hour). Our study demonstrates that Bulgarian children are not an exception

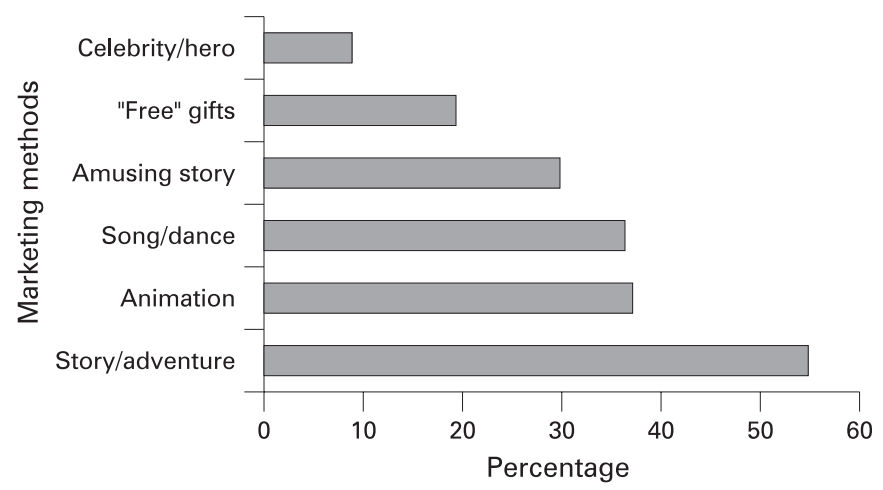

Figure 2 Basic marketing methods used to attract children, given as a percentage of all food advertisements. The sum is over $100 \%$ since many ads apply more than one method. as the frequency of food advertising on Bulgarian TV stations is comparable to that in Austria and Belgium with almost three food ads/hour. So if Bulgarian children still spend on average $2 \mathrm{~h}$ /day watching TV as shown by others, ${ }^{28}$ they will be exposed to an average of six unhealthy food ads. This accounts for about 42 ads weekly or 2190 ads annually — a significant exposure against the data for the TV advertising influence on childhood obesity prevalence, requiring further attention.

All recorded food commercials but one were broadcasted on both private networks, which was comprehensible because of the acting law on radio and TV in Bulgaria (www.cem.bg). According to the law the daily advertising time for the public TV station is 15 minutes, while for the other private/cable networks it is 12 minutes per hour or $15 \%$ of the whole programme time. The law also postulates that all the ads must not be aired during children's programs and stimulate the purchase of the advertised product, taking advantage of their credulity and inexperience. The cited law is adhered to only by public TV channels. We did not find any other specific rules on food advertising to children.

Most of the food ads were shorter than the non-food ads, which might be associated with the sophisticated marketing strategies used for children's easier comprehension as direct stimulation, bright colours, lively music, young actors, their amount and reiteration. In 2004 Powell et al showed that $54 \%$ of the food commercials were 30 seconds long compared to $95 \%$ in $1980,{ }^{29}$ thus also showing a tendency towards shortening.

It is evident from the literature that the food/beverage commercial marketing to children is dominated by unhealthy products, with very little promotion of fruits, vegetables and other healthy choices. ${ }^{27}{ }^{30}$ Our findings showed that one-third of the total product advertising seen by Bulgarian children was in foods/beverages, a figure similar to previous studies. ${ }^{26} 2931$ Almost all recorded food ads did not support the current Bulgarian dietary recommendations for healthy and balanced children's eating, optimum health and avoidance of obesity (www.mh.government.bg/norm_acts.php). The results are in complete compliance with previous international research work from both the developed ${ }^{5} 131832$ and developing world. ${ }^{33}$

The greater children's exposure to unhealthy food advertising in the mornings of the weekend days, when the children are not at school, are at home resting and watching particular TV programmes (cartoons, shows) not requiring parental supervision, should be regarded as a clever marketing method.

This study revealed a wide range of sophisticated and tricky creative strategies used to promote the brand products both directly and indirectly to susceptible children, such as misleading information about the products, popular theme appeals, 
messages and associations attractive to children. These findings coincide with the results of previous research. ${ }^{26} 30{ }^{31}$ There were health-related messages in about one-quarter of the recorded food ads, possibly because advertisers expect children to be more interested in the food's taste than in its disease-fighting properties. The most common health-related message in our sample was that the advertised product contained some kind of natural ingredients. Several studies are in conformity with our results, ${ }^{34}$ as in 1999 Byrd-Bredbenner et al found that almost $30 \%$ of the food ads promoted food using health and nutrition facts $^{25}$; in 2007 the Kaiser Family Foundation reported that almost $18 \%$ of all food ads contained health claims, with $8 \%$ for "essential nutrients". ${ }^{31}$ Other commonly employed marketing methods were the use of famous songs, free gifts and toys, usually a part of a collectable set from several purchases, endorsement from movie/sports celebrities, animated heroes, etc., with the only designation to enhance children's request for a particular food brand. This advertising to children seems very consistent throughout the world, as shown by others. ${ }^{35}$

The characteristics of the participating actors in the ads also conveyed subtle messages about food and eating. In our sample, male actors were slightly overpresented probably implying strength and healthiness. Furthermore, obesity "occurred" among televised characters far less frequently than in the general population. This prevalence of average-sized and thin characters in our sample had an implicit "mixed" message, suggesting that everyone could eat frequently, low-fibre foods, high in fat, sugar and/or salt and remain slender. ${ }^{24} 34$

Children need to be protected from the aggressively targeted promotions of unhealthy foods during children's TV programmes. ${ }^{37}$ According to the Hawkes' report ${ }^{36}$ and the World Health Organization (WHO) Global Strategy on Diet, Physical activity and Health, ${ }^{37}$ food ads "must not: be misleading and take advantage of the children's credulity; be harmful to their physical, mental or moral health; stimulate the overconsumption of unhealthy foods, etc". Such regulatory approaches exist in more than three-quarters of the countries surveyed in the WHO report. To support the national and international efforts in children's protection against the foods/beverages commercials, an International Obesity Task Force working group accepted "The Sydney Principles". 38

In our country a National Food and Nutrition Action Plan was developed with strategic aims to improve the health of the Bulgarian population by improving nutrition and reduce the risk of diet-related chronic diseases (www.fnap.government.bg). It concerns the years 2005-2010 and includes activities directed to the development of new dietary recommendations and standards for the nutritional content, labelling and marketing of foods, etc. Although we were not able to identify specific regulations for TV food advertising to Bulgarian children, this strategy has stipulated their development in 2008-2010.

Currently some of the world market leaders among food and beverage companies have begun to declare self-regulatory actions to combat the childhood overweight/obesity such as: 1) reformulating products to reduce calories, fat and sugar, and add vitamins; 2) offering smaller portion sizes; 3) clearly labelling and advertising; and 4) promoting nutrition education and physical activity programmes. ${ }^{39}$ Some Bulgarian food producers and dealers are also beginning to strive in this direction, although no visible results can be recognised yet.

In summary our study provides a comprehensive assessment of the amount and type of TV food advertising directed to Bulgarian children. It implies that more activities to reduce the unhealthy food promotion to children are mandatory. Some possible ways could be through restrictions by the type of the advertised food, target group or limits on duration or times shown, as well as parental/self-regulation. We suggest an approach for active promotion of healthy food choices from birth onwards, provided different social and environmental structures/stakeholders, food and advertising industries, media, governmental and non-governmental organisations, schools, health professionals and the society as a whole, adopt this as an important tool in the fight against obesity.

Competing interests: None.

\section{REFERENCES}

1. Reilly JJ, Methven E, McDowell ZC, et al. Health consequences of obesity. Arch Dis Child 2003;88:748-52

2. Iotova V, Tzaneva V, Petrova $\mathrm{K}$, et al. Ten-year trend of obesity among primaryschool children in Bulgaria [abstract]. Horm Res 2003;60(Suppl 2):P1-467.

3. Lobstein T, Baur L. Policies to prevent childhood obesity in the European Union. Eur J Public Health 2005;15:576-9.

4. Certain LK, Kahn RS. Prevalence, correlates, and trajectory of television viewing among infants and toddlers. Pediatrics 2002;109:634-42.

5. Coon KA, Tucker KL. Television and children's consumption patterns. A review of the literature. Minerva Pediatr 2002;54:423-36.

6. Wiecha JL, Peterson KE, Ludwig DS, et al. When children eat what they watch. Impact of television viewing on dietary intake in youth. Arch Pediatr Adolesc Med 2006;160:436-42.

7. Rideout V, Hamel E. The media family: Electronic media in the lives of infants, toddlers, preschoolers and their parents. Menlo Park, CA: The Henry J. Kaiser Foundation, 2006. www.kff.org/entmedia/7500.cfm, 24 May 2006.

8. McGinnis MJ, Gootman JA, Kraak VI, eds. Committee on food marketing and the diets of children and youth. Food marketing to children and youth: threat or opportunity. Institute of Medicine, The National Academics. Washington, DC: National Academies Press, 2006:516.

9. Donkin AJ, Neale RJ, Tilston C. Children's food purchase requests. Appetite 1993;21:291-4.

10. Gortmaker SL, Must A, Sobol AM, et al. Television viewing as a cause of increasing obesity among children in the United States, 1986-1990. Arch Pediatr Adolesc Med 1996;150:356-62.

11. Proctor MH, Moore LL, Gao D, et al. Television viewing and change in body fat from preschool to early adolescence: the Framingham Children's Study. Int J Obes Relat Metab Disord 2003;27:827-33.

12. Lumeng JC, Rahmana S, Appugliese D, et al. Television exposure and overweight risk in preschoolers. Arch Pediatr Adolesc Med 2006;160:417-22.

13. Gamble M, Cotunga N. A quarter century of TV food advertising targeted at children Am J Health Behav 1999:23:261-7.

14. Story $\mathbf{M}$, French $\mathbf{S}$. Food advertising and marketing directed at children and adolescents in the US. Int J Behav Nutr Phys Act 2004;1:3.

15. Taras HL, Gage M. Advertised foods on children's television. Arch Pediatr Adolesc Med 1995; 149:649-52.

16. Boynton-Jarrett R, Thomas TN, Peterson KE, et al. Impact of television viewing on fruit and vegetable consumption among adolescents. Pediatrics 2003;112:1321-6.

17. Borzekowski DL, Robinson TN. The 30-second effect: an experiment revealing the impact of television commercials on food preferences of preschoolers. J Am Diet Assoc 2001;101:42-6.

18. Kotz K, Story M. Food advertisements during children's Saturday morning television programming: Are they consistent with dietary recommendations? J Am Diet Assoc 1994; $94: 1296-300$.

19. Halford JC, Gillepsie J, Brown V, et al. Effect of television advertisements for foods on food consumption in children. Appetite 2004;42(2):221-5.

20. Strasburger VC. Children and TV advertising: nowhere to run, nowhere to hide. J Dev Behav Pediatr 2001;22:185-7.

21. Utter J, Scragg R, Schaaf D. Association between television viewing and consumption of commonly advertised foods among New Zealand children and young adolescents. Public Health Nutr 2006;9(5):606-12.

22. Vereecken CA, Todd J, Roberts C, et al. Television viewing behavior and associations with food habits in different countries. Public Health Nutr 2006;9:244-50.

23. Henderson VR, Kelly B. Food advertising in the age of obesity. J Nutr Educ Behav 2005;37:191-6.

24. Tirodkar MA, Jain A. Food messages on African American television shows. Am J Public Health 2003;93:439-41.

25. Byrd-Bredbenner C, Grasso D. What is television trying to make children swallow? content analysis of the nutrition information in prime-time advertisements. J Nutr Educ 2000;32:187-95.

26. Neville L, Thomas M, Bauman A. Food advertising on Australian television: the extent of children's exposure. Health Promot Int 2005;20(2):105-12.

27. Dibb S, Harris L. A spoonful of sugar. Television food advertising aimed at children: an international comparative study. London, UK: Consumers International, 1996. 
28. Petrova K, lotova V, Zlatarov I. [Organization of the everyday regime of students of early school age in the realities of high degree of urbanization]. Hygiene and Healthcare 2001;:XLV(2-3):6-9 (article in Bulgarian).

29. Powell LM, Szczypka G, Chaloupka FJ. Exposure to food advertising on television among US children. Arch Pediatr Adolesc Med 2007;161:553-60.

30. Matthews A, Cowburn G, Raynor M, et al. The marketing of unhealthy food to children in Europe: a report of phase 1 of the children, obesity and associated chronic diseases project. Brussels, Belgium: European Heart Network, 2005. www.ehnheart. org, 3 March 2006.

31. Gantz W, Schwartz N, Angelini JR, et al. Food for thought. Television food advertising to children in the United States. Menlo Park, CA: The Henry Kaiser Family Foundation, 2007. www.kff.org, 28 March 2007.

32. Hastings G, McDermott L, Angus KW, et al. The extent, nature and effects of food promotion to children: a review of the evidence. Geneva: World Health Organization, 2006. www.who.int/dietphysicalactivity/publications/Hastings paper marketing.pdf

33. Maryam A, Mehdi MR, Masood K, et al. Food advertising on Iranian children's television: A content analysis and an experimental study with junior high school students. Ecol Food Nutr 2005:44(2):123-33.
34. Harrison K, Marske AL. Nutritional content of food advertised during the television programs children watch most. Am J Public Health 2005;95(9):1568-74.

35. Buijzen M, Valkenburg PM. Appeals in television advertising: A content analysis of commercials aimed at children and teenagers. Communications 2002;27(3):349-64.

36. Hawkes C. Marketing food to children: the global regulatory environment. Geneva: World Health Organization, 2004. www.who.int/dietphysicalactivity/publications/en/

37. WHO Global Strategy on Diet, Physical Activity and Health. Geneva: World Health Organization, 2004. www.who.int/dietphysicalactivity/en, 10 April 2007

38. The International Obesity Task Force. The Sydney Principles: Guiding principles for achieving a substantial level of protection for children against the commercial promotion of foods and beverages, 2006. www.iotf.org/sydneyprinciples/. Accessed 6 August 2007.

39. Lang T, Rayner G, Kaelin E. The food industry, diet, physical activity and health: a review of reported commitments and practice of 25 of the world's largest food companies. London: Centre for Food Policy, City University, 2006. www.city.ac.uk/ press/The\%20Food\%2OIndustry\%20Diet\%20Physical\%20Activity\%20and\%20Health. pdf, 13 May 2006.

\section{Calling European Paediatric Research Networks}

The European Medicines Agency (EMEA) is fully committed to facilitating a "virtual" European Network through linking all existing national and European networks, investigators and centres with specific expertise in the performance of paediatric studies. This commitment is grounded in the Paediatric Regulation EC No 1901/2006, as amended (Article 44), which has the objectives:

- to ensure that medicinal products used to treat children are subject to ethical research of high quality and are appropriately authorised for use in the paediatric population

- to improve the information available on the use of medicinal products in the various paediatric populations

- to achieve the above without subjecting the paediatric population to unnecessary clinical trials

Clinical trials in the paediatric population require specific expertise, specific methodology and, in some cases, specific facilities. They should be performed by appropriately trained investigators.

The EMEA European Network aims are:

- to identify, coordinate and link together existing networks, existing national and community initiatives and study centres in order to build the necessary competences at community level

- to ensure efficient, timely communication and exchange of information between networks

- to be a source of information and expertise for health professionals

- to provide a forum for scientific discussion related to paediatric clinical trials with all stakeholders, where necessary

- to take account of community and third country data

- to help facilitate cooperation

- to avoid unnecessary duplication of studies

This network will:

- provide a central source of information and expertise for industry

- contribute to strengthening the foundations of the European research area in the context of community framework programmes for research, technological development and demonstration activities

- benefit the paediatric population

An implementing strategy was adopted 26 January 2008 by the EMEA management board. http://www.emea.europa.eu/pdfs/human/paediatrics/54352307en.pdf

There are many advantages to joining the network:

- be visible as a potential site for externally sponsored clinical trials

- be at the forefront of medicinal development

- be consulted for your expert opinion when paediatric investigation plans in your field of expertise are discussed and developed

- share the skills and expertise of other national and European networks

- shape and influence future development in paediatric research

Joining the network is easy; contact us with your details via enpremea@emea.europa.eu.

Contact details will allow the EMEA to set up an initial mailing list of networks, who will be invited for an implementation meeting to be held at the EMEA in London, planned for February 2009.

The meeting will:

- discuss and agree mandate and objectives

- define scientific and operational quality standards and recognition criteria

- implement coordinating group 